\title{
The use of visual and automatized behavioral markers to assess methodologies: a study case on PIT-tagging in the Alpine newt
}

\author{
Laurane Winandy • Mathieu Denoël
}

Published online: 27 February 2011

(C) Psychonomic Society, Inc. 2011

\begin{abstract}
In various research fields, biomarkers are now widely used as tools for assessing individual integrity. The recent advances in quantification methods for behavioral patterns, such as computerized video-tracking procedures, make them valuable biomarkers. However, the corollary of these novelties is that they remain relatively unknown and unused. In this study, we show that such tools can assess the validity of research methods, such as individual recognition. To demonstrate this, we employed, as a model, a marking method (passive integrated transponder [PIT] tagging) widely used in amphibians. Detailed visual observations and video-tracking methods were complementary in highlighting components at different behavioral scales: locomotion, feeding, and breeding. We illustrate the scientific and ethical adequacy of the targeted marking method but also suggest that more studies should integrate behavioral analyses. Such biomarkers are a powerful tool for assessing conservation concerns when other techniques cannot detect detrimental effects.
\end{abstract}

Keywords Amphibian · Behavior · Biomarker P PIT tag ·

Video tracking

Researchers have studied behavioral patterns in order to understand the characteristics of species and individuals,

\footnotetext{
L. Winandy $(\bowtie) \cdot$ M. Denoël $(\bowtie)$

Laboratory of Fish and Amphibian Ethology,

Behavioural Biology Unit,

Department of Environmental Sciences,

University of Liège,

22 Quai van Beneden,

4020 Liège, Belgium

e-mail: L.winandy@student.ulg.ac.be

M. Denoël

e-mail: Mathieu.Denoel@ulg.ac.be
}

categorized into tactics and adaptations, and they also have sometimes been used in other fields, such as conservation biology (Caro, 2007; Shuster \& Wade, 2003). Similar to what is done on a molecular or physiological basis (Cooke \& O'Connor, 2010), an emerging practice has been to use them as biomarkers - that is, as a tool in evaluation and assessment processes (Fasulo et al., 2010). For instance, behavioral patterns thus have become model systems used to understand how pesticides and other chemicals can affect the integrity of organisms (Denoël et al., 2010; Giusi et al., 2010; Scott \& Sloman, 2004). Yet despite the great potential of behavioral markers, they are still little used in many research fields where other life marks, such as life history traits, have historically been preferred (Sutherland, 1998). Video-tracking, a technique benefitting from the recent developments in computer sciences, is now available for quantifying various behavioral patterns that are derived from space use across time (Delcourt, Becco, Vandewalle, \& Poncin, 2009; Kato et al., 2004). Its recent use as a biomarker shows its powerful efficacy in laboratory assessments (Denoël et al., 2010; Eddins, Cerutti, Williams, Linney, \& Levin, 2010). In a large number of physiological, ecological, and behavioral studies, individual recognition of each member of a studied population is a necessity (Barron, Butler, McDonnell \& Ward, 2009; Coltherd, Morgan, Judge, Smith \& Hutchings, 2010; Gubili et al., 2009). This allows repeated measures on the same organisms, identification of tactics, and application of effective conservation measures (Caro, 2007; Martin \& Bateson, 2007; Shuster \& Wade, 2003). When natural marks cannot be used for individual identification, many techniques are now available to mark a large variety of animals, such as fish (Winter, Jansen, Adam, \& Schwevers, 2005), amphibians (Donnelly, Guyer, Juterbock \& Alford, 1994; Pope \& Matthews, 2001; Schulte, Küsters, \& Steinfartz, 2007), reptiles (Jemison, Bishop, May, \& Farrell, 1995; Keck, 1994), birds (Nicolaus, 
Bouwman, \& Dingemanse, 2008), and mammals (Morley, 2002). The most commonly used methods are tag attachment, tattooing, toe-clipping, burning, and PIT-tagging (Faber, 2001). A PIT-tag is an electronic microchip with a unique code (Donnelly et al., 1994). It is implanted directly in the animal's body and has the advantage of being permanent, reliable, and easily readable. Because of these benefits, PIT-tags are becoming widely used and preferred over techniques such as tattooing and toe-clipping, which are temporary because of color attenuation and toe regeneration (Faber, 2001; Gibbons \& Andrews, 2004). The PIT-tag also allows distance detection and thus prevents potential stress of recapture and manipulation (Cucherousset, Marty, Pelozuelo, \& Roussel, 2008; Hill, Zydlewski, Zydlewski, \& Gasvoda, 2006; Mellor, Beausoleil, \& Stafford, 2004). However, PITtags are expensive (Arntzen, Goudie, Halley, \& Jehle, 2003) and require a minimal animal size for insertion (Gibbons \& Andrews, 2004).

A major component of marking technique choice is that it should not affect the integrity of organisms (Dennis, Newberry, Cheng, \& Estevez, 2008; Ferner, 2010; Gibbons \& Andrews, 2004). This is important in order to avoid biases in analyses (Winter et al., 2005), but also for ethical considerations (May, 2004). In this respect, most research programs now undergo an ethical evaluation and are obligated to minimize disturbance on animals (May, 2004; Wolfensohn \& Lloyd, 2003; see also Directive 2010/63/EU of the European Parliament and of the Council of 22 September 2010).

Most research on the possible effects of the PIT-tag has been conducted on fish and has indicated an adequacy of PIT-tagging. No detrimental effect has been found on survival (Bolland, Cowx, \& Lucas, 2009; Navarro et al., 2006; Ombredane, Baglinière, \& Marchand, 1998), growth (Acolas, Roussel, Lebel, \& Baglinière, 2007; Knaepkens, Maerten, Tudorache, De Boeck, \& Eens, 2007; Lee, Park, \& Cho, 2009), reproduction (Baras, Malbrouck, Houbart, Kestemont, \& Mélard, 2000; Mahapatra et al., 2001), feeding behavior (Newby, Binder, \& Stevens, 2007; Park \& Park, 2009), and swimming ability (Moore, Russell, \& Potter, 1990; Mueller, Moursund, \& Bleich, 2006;). The few studies on snakes have shown that PIT-tagging does not affect growth, movement, and speed (Keck, 1994; Jemison et al., 1995). In newts (Faber, 1997; Jehle \& Hödl, 1998; Perret \& Joly, 2002), studies have focused primarily on mortality, growth, fertility, and wound recovery inflicted by the implantation. Neither survival nor growth was affected by the electronic chip (Cummins \& Swan, 2000; Fasola, Barbieri, \& Canova, 1993; Ott \& Scott, 1999). It appears that PIT-tagged individuals survived under both natural and captive conditions and that PIT-tagged salamanders became pregnant under natural conditions (Steinfartz, Stemshorn, Kuesters, \& Tautz, 2006). Behavioral patterns have thus been too rarely used to evaluate the effect of PIT-tagging on organisms (Winter et al., 2005). Particularly in newts - although no abnormal behavior has been observed in the field (Faber, 1997) - no controlled experiments have been conducted to assess the impact of PITtagging on behavior. Although there has been no evidence of negative impact on the mortality and fitness of newts (Jehle \& Hödl, 1998), behaviors might be altered and, thus, affect fitness in a natural situation. Therefore, there is a need for complementary studies to assess potential effects at the behavioral level.

In this study, we show the value of using various behavioral markers to assess the potential effect of a marking technique, PIT-tagging. We took into account simple and complex behaviors at different scales, such as locomotion, feeding, and breeding. We integrated standardized visual observations, as well as new computerized techniques, - that is, the latest software in video-tracking analysis (Noldus Ethovision XT7). We used newts as models to test our methods because (1) they are used in several research fields (Kopecki, Vojar, \& Denoël, 2010; Šamajová \& Gvoždik, 2010), (2) marking them has not yet been evaluated at the behavioral level, and (3) video tracking has never been used on these organisms.

\section{Method}

\section{Study organism}

Amphibians exhibit a large diversity of patterns and habitat use and reveal potential medical or veterinary applications (Clarke, 1997; D'Agostino et al., 2007). The Alpine newt (Mesotriton alpestris) is a widely spread species in Europe (Denoël, 2007), in which PIT-tagging has been repeatedly used (Denoël, Lena, \& Joly, 2007; Faber, 1997; Perret \& Joly, 2002). Alpine newts are aquatic during the breeding season and terrestrial throughout the rest of the year. In the aquatic phase, they use various microhabitats and prey (Denoël \& Andreone, 2003). Sexual interactions consist of several male courtship displays toward the female (Denoël, Mathieu, \& Poncin, 2005) and occur mainly during the morning in association with high locomotor activity (Martin, Joly, \& Bovet, 1989).

\section{Sampling and laboratory maintenance}

We caught 32 adult Alpine newts (16 individuals of each sex) in a pond in Pays de Herve (Province of Liege, Belgium; $50^{\circ} 34^{\prime} 20^{\prime \prime} \mathrm{N}, 5^{\circ} 42^{\prime} 40^{\prime \prime} \mathrm{E}$; elevation a.s.1. $201 \mathrm{~m}$ ) at the start of the breeding season (April 1, 2010). Newts were brought directly to the laboratory after a 20 -min drive in boxes $(3 \mathrm{~L})$ containing aquarium cotton filter and water kept at a low temperature. The newts were randomly 
distributed, 4 by 4 ( 2 males and 2 females) in eight tanks $(60 \times 60 \mathrm{~cm}, 40-\mathrm{cm}$ water level). The bottoms of the aquariums were covered with flat stones. We also provided three types of shelter: behind an oblique stone, under a roller device (for spawning), and on the ground between the stones. The water temperature was maintained at an average of $15.1^{\circ} \mathrm{C}\left(S E=0.3^{\circ} \mathrm{C}\right)$, and the photoperiod followed the natural cycle of the capture place, starting at 13-h light:11$\mathrm{h}$ dark and ending at 14-h 30-min light:9-h 30-min dark at the end of the experiment (30-min increments of the day phase every 15 days). Subjects were fed every 2 days, in the afternoon, with $500 \mathrm{mg}$ of Chironomus larvae per tank. All newts were released into their habitat of capture after the end of the experiment (May 21, 2010).

\section{Pit-tagging}

The day after capture, half of the newts (four of the eight tanks) were marked with a PIT-tag (RFID Mark, $134.2 \mathrm{kHz}$, Reseaumatique, $9 \times 1.4 \mathrm{~mm}, 33 \mathrm{mg}$ ). The PIT-tag was injected under the skin at the level of the hindlimbs and pushed in direction of the forelimbs. The presence of the PIT-tag was verified throughout the experiment with a RFID reader (Reseaumatique, RT 100). The marked newts constituted the experimental group $(n=16)$, while the other newts were used as a control group $(n=16)$.

\section{Experimental procedure}

Visual observation The observation of newts for a few days prior to the experiment allowed us to establish a list of behavioral units displayed by newts during daytime. By using sketches of unique spots and special features of the newts, we were able to visually recognize the 4 individuals from each tank. We selected the following behavioral units for our study: courtship (sexual acts of the male toward the female), shelter use (presence in one of the shelters), and feeding (eating chironomid larvae).

Courtship and shelter use data collection consisted of an observation session in the morning (9:30 to 11:30 a. $\mathrm{m}$.) and an observation session in the afternoon (14:30 to 16:30 p.m.). At each session, we used a focal sampling method (Martin \& Bateson, 2007) 10 times for a minute for each aquarium. The observation sessions took place during the first 10 days after implantation of the PIT-tag (period 1) and during the last 10 days before release of the newts (period 2). The observations were replicated 5 times at each morning and afternoon session of the two periods (a total of 10 days).

We assessed feeding behavior by measuring the food detection latency (time from the introduction of Chironomus larvae at the center of the aquarium to the first capture by each newt). We observed four aquariums simultaneously for $20 \mathrm{~min}$ and replicated this during 5 days for the two periods (a total of 10 days). The feeding sessions did not take place on the same days as the other behavioral observations

Video tracking We used Ethovision ${ }^{\circledR}$ XT 7 (Noldus Information Technology), which is an automated videorecording system that allows analysis of movement and activity. We recorded 4 newts at the same time. Each newt was placed in a separate arena with a $19-\mathrm{cm}$ diameter filled with water $(15-\mathrm{cm}$ depth). We conducted this experiment between the two periods of visual observations. Newts were given $30 \mathrm{~min}$ of habituation before we recorded their behavior for $10 \mathrm{~min}$.

A Sony video camera (DCR-HC90E) recorded the subjects' movement and converted it to a digital signal. Then the system detected the subject by grayscale contrast with the background and determined its size and position on each image $(5 / \mathrm{sec})$. From these images we established individual tracks (Fig. 1) and transformed them into a series of dependent variables that quantified the behavior. The selected variables were distance (in centimeters), space use (distance to center point, in centimeters), moving duration (in seconds), and velocity (in centimeters per second).

Statistical procedure

The replicated visual observations of behaviors were tested using a general linear model that accounted for repeated measures. We tested the video-tracking analysis using general linear models, introducing size as a covariate. To achieve normality, continuous data from visual observations

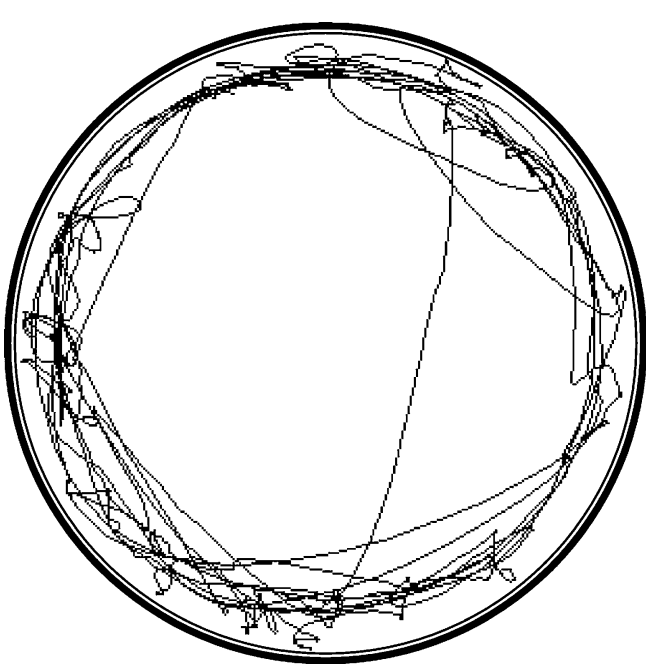

Fig. 1 Example of a video track using Ethovision XT7 
were normalized by the square-root transformation before computing the parametric significance test (Sokal \& Rohlf, 1995). For all tests, we set an a priori maximum error risk of .05. We conducted all statistical analyses in Statistica 9.1 (Statsoft-France, 2010).

\section{Results}

\section{Visual observation}

PIT-tag and its interaction with sex and time period had no significant effect on food detection latency (Mean $\pm S E=$ $464 \pm 70 \mathrm{sec}$ and $507 \pm 75 \mathrm{sec}$, respectively, for marked and control newts; see Table 1 and Fig. 2a). There was also no significant effect of marking and its interaction with time on courtship behavior, regardless of time period $(0.99 \pm 0.27$ per session of observation and $0.78 \pm 0.19$ per session of observation, respectively, for marked and control newts; see Table 1 and Fig. 2b). There was a significant effect of PITtag on shelter use, but not of the interaction with sex and time (see Table 1 and Fig. 2c): Marked newts used shelters less than did controls $(6.31 \% \pm 1.04 \%$ and $9.5 \% \pm 1.94 \%$, respectively, for marked and control newts). Fifteen percent of the difference between groups was explained by PIT-tags.

\section{Video-tracking analysis}

We had to pull out two tracks of the analysis because 2 newts ( 1 female and 1 male) escaped from the arena during the recording. There was no significant difference between the marked and control groups on the total distance (722 \pm $77.7 \mathrm{~cm}$ and $544 \pm 83.3 \mathrm{~cm}$, respectively; see Table 2 and Fig. 3a), distance to center point $(6.39 \pm 0.13 \mathrm{~cm}$ and $6.32 \pm$ 0.14 , respectively; Fig. 3b), moving duration (125 $\pm 16.2 \mathrm{sec}$

Table 1 Visual observations: General linear model with repeated measures evaluating the effect of PIT-tag on behavioral patterns and its interaction with sex and time

\begin{tabular}{llll}
\hline Behavior & Factors & $F$ & $P$ \\
\hline Feeding & PIT-tag & $F(1,28)=1.19$ & .28 \\
& PIT-tag $\times$ sex & $F(1,28)=0.93$ & .34 \\
& PIT-tag $\times$ time & $F(9,252)=0.34$ & .96 \\
& PIT-tag $\times$ sex $\times$ time & $F(9252)=0.80$ & .62 \\
Courtship & PIT-tag & $F(1,14)=0.55$ & .47 \\
& PIT-tag $\times$ time & $F(3,42)=1.91$ & .14 \\
Shelter use & PIT-tag & $F(1,28)=5.00$ & $\mathbf{. 0 3}$ \\
& PIT-tag $\times$ sex & $F(1,28)=2.63$ & .12 \\
& PIT-tag $\times$ time & $F(3,84)=0.18$ & .91 \\
& PIT-tag $\times$ sex $\times$ time & $F(3,84)=1.53$ & .21 \\
\hline
\end{tabular}

Significant values are highlighted in bold and $89 \pm 17 \mathrm{sec}$, respectively; Fig. 3c), and velocity (1.21 \pm $0.13 \mathrm{~cm} / \mathrm{sec}$ and $0.92 \pm 0.14 \mathrm{~cm} / \mathrm{sec}$, respectively; Fig. 3d).

\section{Discussion}

In this study, we used two types of methods to measure behavior. The replicated visual observations allowed analysis of very important and consistent behavior, such as courtship, feeding, and shelter use. The use of a newly developed video-tracking software (Ethovision ${ }^{\circledR}$ XT 7) allowed us to quantify variables such as distance, movement, and velocity. This computerized method has an advantage over standard visual methods in that it determines in a very accurate way the position of an individual and allows processing of a large amount of data in a relatively short time period (Delcourt et al., 2006; Delcourt et al., 2009; Denoël et al., 2010; Eddins et al., 2010). Both methods proved to be complementary with respect to each other in analyzing different behavioral aspects: Visual observations assess complex behaviors such as feeding and breeding, while video tracking assesses more quantitative patterns of locomotor activity.

No individuals died during the experiment, and marked newts recovered quickly after surgery. No loss or expulsion of PIT-tags occurred during the whole study. Although surgical glue could be used to avoid loss (Jehle \& Hödl, 1998), PIT-tag persistence without glue in our study shows that, if well inserted, they work without using glue (see also Gibbons \& Andrews, 2004). Furthermore, surgical glue could have a dermatological, allergic, and respiratory toxicity (Leggat, Smith, \& Kedjarune, 2007). Since a PITtag can remain on a newt for the duration of its life, it is thus regarded as an appropriate method for marking newts. PIT-tagging reduces stress imposed by handling the animals, because the portable PIT antenna negates the need for recapture (Charney, Letcher, Haro, \& Warren, 2009; Faber, 1997). The portable detector (which can be water resistant) allows identification of marked newts directly in their aquatic habitat (Cucherousset et al., 2008).

The feeding behavior of marked newts was not disturbed, resulting in similar food detection latency in both groups. These results are consistent with those obtained in the framework of fish research (Moore et al., 1990; Newby et al., 2007) and sea urchins (Lauzon-Guay \& Scheibling, 2008). Another essential behavioral pattern, courtship, occurred frequently during our experiment. It also was not affected by the marking procedure, an aspect that has so far not been covered by previous studies. In terms of shelter use, we observed a difference between groups. While unmarked newts preferred to hide, marked newts were more often in open areas. In the wild, this difference could have predation consequences, but the effect is unknown. It 
Fig. 2 Visual observations:

Food detection latency (a), courtship occurrence (b), and shelter use frequency (c) of newts as a function of PITtags presence (mean $\pm S E$ a nd $S D$ values). See Table 1 for statistical results. Open boxes, first period of observation; shaded boxes, second period of observation
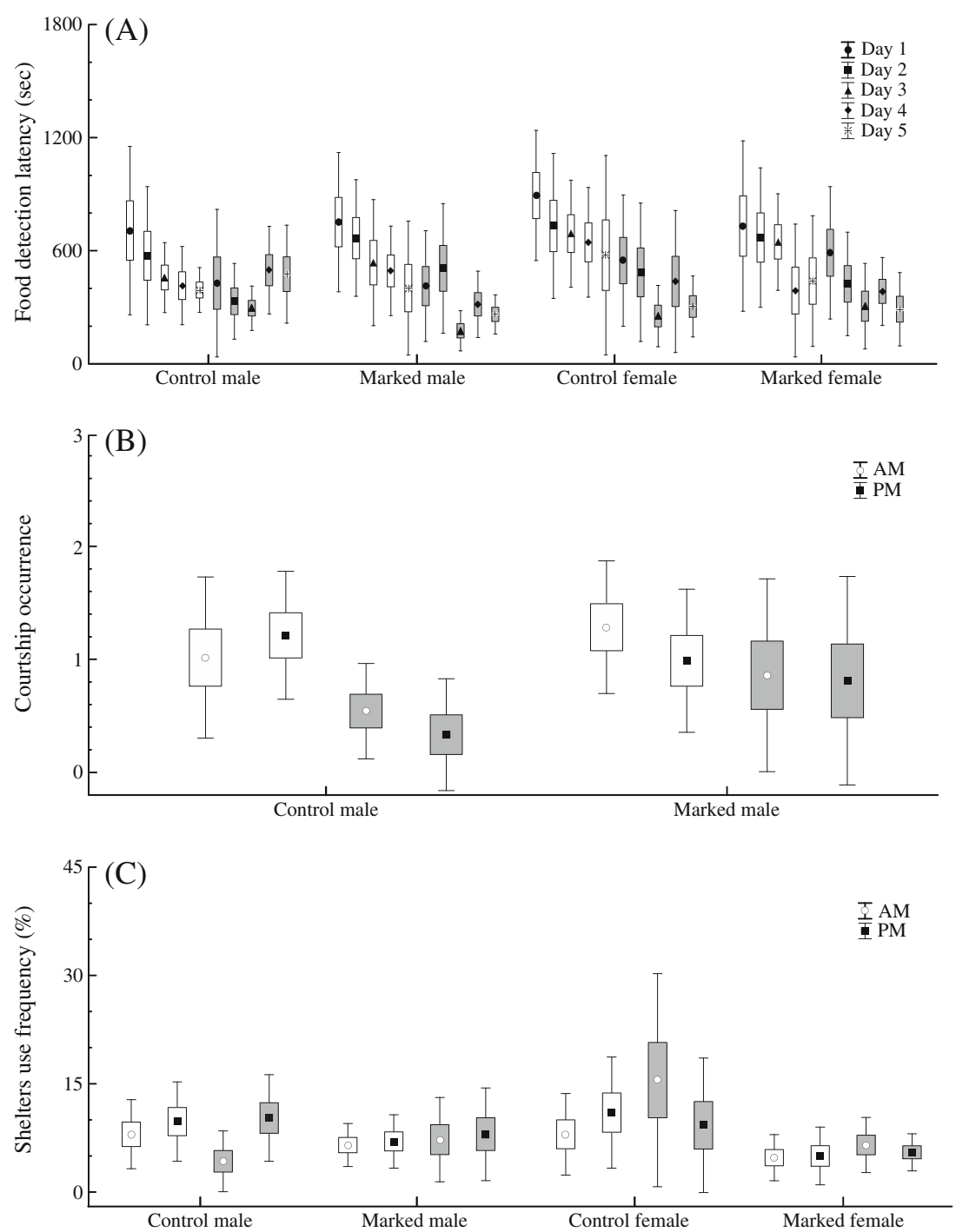

is possible that more active newts could find better prey and mates but could also be more vulnerable to predators such as fish. Fraker (2008) found that the activity level of green frog tadpoles reflects a trade-off between predation risk and feeding: The tadpoles reduced their activity level when predators were present. In a study on salmon, Adams, Rondorf, Evans, Kelly, and Perry (1998) evaluated predator avoidance of juvenile marked fish and found that predators (small-mouth bass) caught significantly more marked fish than unmarked fish. In contrast with our visual observation highlighting a different use of habitat, our video-tracking analyses did not show any difference between groups: Both marked and control groups moved similarly along the edge of their arena.

Although our analysis of video tracks did not show any significant effect of marking on movement, distance, and velocity, we can observe in the Fig. 3 that marked females showed a tendency to be more active. Perret and Joly
(2002) also studied the effect of PIT-tagging on the Alpine newt and found that marked females laid significantly more eggs than did unmarked females. They hypothesized that the increased production of eggs could be a response to stress caused by implantation of the PIT-tag. It is possible that stress induced by marking affects the fertility and activity of females, but no definite conclusions can be made. Winter, Jansen, Adam and Schwevers (2005) also detected a difference in the activity of marked eels: They were less active than the control group. They assumed that the fish had not recovered from injury after surgery. However, with time, this difference in activity between groups did not decrease. It is difficult to assess whether stress is a result of surgery or whether of the presence of the PIT-tag itself. Only surgery with all the newts, without inserting a chip in the control group, could test this hypothesis. Close, Fitzpatrick, Lorion, Li, and Schreck (2003) addressed this in a study on the lamprey. They did 
Table 2 Video-tracking analyses: General linear model evaluating the effect of PIT-tag on locomotor activity patterns and its interaction with sex. Distance moved is given in centimeters, distance to center point in centimeters, moving duration in seconds, and velocity in centimeters/second. Size was introduced as covariate

\begin{tabular}{llll}
\hline Variables & Factors & $F$ & $P$ \\
\hline Distance moved & PIT-tag & $F(1,25)=2.38$ & .14 \\
& PIT-tag $\times$ sex & $F(1,25)=2.95$ & .10 \\
& Size (covariate) & $F(1,25)=0.39$ & .54 \\
Distance to center point & PIT-tag & $F(1,25)=0.14$ & .71 \\
& PIT-tag $\times$ sex & $F(1,25)=2.39$ & .13 \\
Moving duration & Size (covariate) & $F(1,25)=0.01$ & .92 \\
& PIT-tag & $F(1,25)=2.25$ & .15 \\
& PIT-tag $\times$ sex & $F(1,25)=2.51$ & .13 \\
Velocity & Size (covariate) & $F(1,25)=0.35$ & .56 \\
& PIT-tag & $F(1,25)=2.11$ & .16 \\
& PIT-tag $\times$ sex & $F(1,25)=2.90$ & .10 \\
& Size (covariate) & $F(1,25)=0.48$ & .50 \\
\hline
\end{tabular}

not compare behavior between marked and control groups but compared blood glucose level, which is a physiological way to assess stress response (Mesa, Bayer, \& Seelye, 2003). They found no short-term and long-term difference in glucose concentration between the two groups. This suggests that the marking in question was not more stressful than handling the animal.

However, it should be noted that the small size of Alpine newts makes them more vulnerable to potential pressure of the chip on internal organs. This could cause stress and explain the observed variations. Most studies that have taken into consideration body size have assessed the impact of PIT-tagging not on behavior, but on growth. The absence or delay of growth can be explained by stress induced by tagging. In fish studies, while some authors did not report any effect of PIT-tagging on growth (Acolas et al., 2007; Lee et al., 2009; Navarro et al., 2006), others researchers found a reduction in short-term growth (Baras, Westerloppe, Mélard, \& Philippart, 1999; Lacroix, Knox, \& McCurdy, 2004; Sigourney, Horton, Dubreuil, Varaday \& Letcher, 2005). Cucherousset, Paillisson, and Roussel (2007) found that the effect on growth was independent of the size of their studied fish, whereas Greenstreet and Morgan (1989) determined that a minimum size of $160 \mathrm{~mm}$ for Atlantic salmon prevented a tag effect on growth. A tag can represent from $4.6 \%$ to $10.4 \%$ of the weight of a fish smaller than $120 \mathrm{~mm}$ (Adams et al., 1998). However in our study, we used PIT-tags that represented only $0.1 \%$ of the weight of the newts - that is, much less than in the previously mentioned studies.

\section{Conclusions}

These results add to those of previous studies in suggesting that PIT-tagging is not destructive and has no major invasive effects on behavior. Nevertheless, since some differences were outlined, more in-depth studies on marked animals, both in the laboratory and in the field, are recommended to assess potential invasive aspects of marking on behavior. Since PITtagging is a preferred marking method in the field, it is essential to ensure that it does not influence the behavior of the studied organisms. The size of animals is an essential factor when a microchip implantation method is used. Fortunately, technological progress now has reduced the size of PIT-tags: only $1.4 \times 9 \mathrm{~mm}$ in this study, as against $2 \times 12 \mathrm{~mm}$ up until only a couple of years ago. The smallest PIT-tags are much more expensive and can minimize effects, yet no prior studies have compared the effects of various mark sizes. Since they are now available, we recommend using small marks, except for large organisms or when detection distances are important (Cucherousset, Roussel, Keeler, Cunjak, \& Stump, 2005).

Finally, this study demonstrates that more studies should integrate quantitative behavioral analyses, such as video
Fig. 3 Video-tracking analyses:

Total distance moved (in centimeters) (a), total distance to center point (in centimeters) (b), moving duration (in seconds) (c), and velocity (in centimeters/second) (d) of newts as a function of PITtags presence and sex (mean \pm $S E$ and $S D$ values). See Table 2 for statistical results
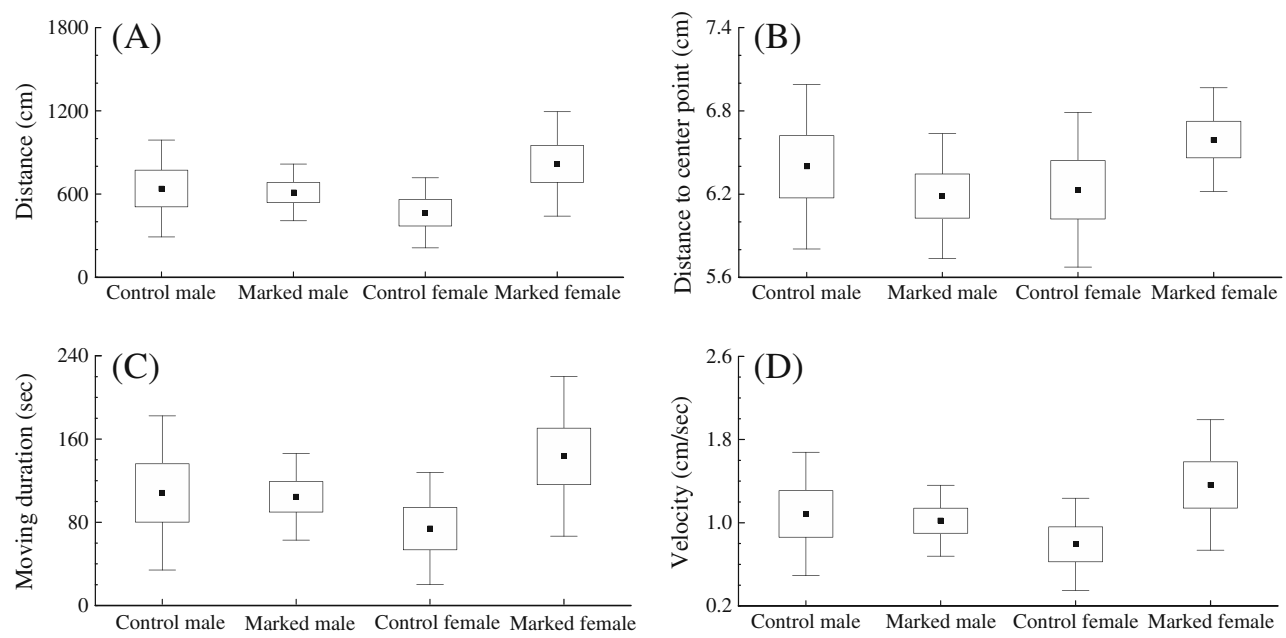
tracking, to estimate the adequacy of methodologies. These behavioral methods proved to give complementary, reliable, and straightforward results. In our study, we applied them to a marking method, but they could also be similarly applied in other fields. Like the biomarkers used in physiology (Cooke \& O'Connor, 2010), quantitative ethology is an important tool for validating experimental research and assessing conservation concerns when other techniques lack the sensitivity necessary to detect detrimental effects (Denoël et al., 2010).

Author note We are very grateful to Kristen Richardson and the reviewers for their constructive comments on the manuscript. The collecting permit was issued by the Service Public de Wallonie (SPW). The study was carried out in an agreed-on laboratory at the University of Liège, and the research project was accepted by the ethical commission of the university. M. Denoël is a Research Associate at the Fonds National de la Recherche Scientifique (F.R.S.-FNRS). This research benefited from a F.R.S.-FNRS (Crédit aux chercheurs 1.5.040.10) and a SPW (33.01.11/GF/2009) public grant.

\section{References}

Acolas, M. L., Roussel, J. M., Lebel, J. M., \& Baglinière, J. L. (2007). Laboratory experiment on survival, growth and tag retention following PIT injection into the body cavity of juvenile brown trout (Salmo trutta). Fisheries Research, 86, 280-284.

Adams, N. S., Rondorf, D. W., Evans, S. D., Kelly, J. E., \& Perry, R. W. (1998). Effects of surgically and gastrically implanted radio transmitters on swimming performance and predator avoidance of juvenile chinook salmon (Oncorhynchus tshawytscha). Canadian Journal of Fisheries and Aquatic Sciences, 55, 781-787.

Arntzen, J. W., Goudie, I. B. J., Halley, J., \& Jehle, R. (2003). Cost comparison of marking techniques in long-term population studies: PIT-tags versus pattern maps. Amphibia-Reptilia, 25, $305-315$.

Baras, E., Malbrouck, C., Houbart, M., Kestemont, P., \& Mélard, C. (2000). The effect of PIT tags on growth and physiology of age-0 cultured Eurasian perch Perca fluviatilis of variable size. Aquaculture, 185, 159-173.

Baras, E., Westerloppe, L., Mélard, C., \& Philippart, J.-C. (1999). Evaluation of implantation procedures for PIT-tagging juvenile Nile tilapia. North America Journal of Aquaculture, 61, 246-251.

Barron, G. U., Butler, F., McDonnell, K., \& Ward, S. (2009). The end of the identity crisis? Advances in biometric markers for animal identification. Irish Veterinary Journal, 62, 204-208.

Bolland, J. D., Cowx, I. G., \& Lucas, M. C. (2009). Evaluation of VIE and PIT tagging methods for juvenile cyprinid fishes. Journal of Applied Ichthyology, 25, 381-386.

Caro, T. (2007). Behavior and conservation: A bridge too far? Trends in Ecology \& Evolution, 22, 394-400.

Charney, N. D., Letcher, B. H., Haro, A., \& Warren, P. S. (2009). Terrestrial passive integrated antennae for tracking small animal movements. Journal of Wildlife Management, 73, 1245-1250.

Clarke, B. T. (1997). The natural history of amphibian skin secretions, their normal functioning and potential medical applications. Biological Reviews, 72, 365-379.

Close, D. A., Fitzpatrick, M. S., Lorion, C. M., Li, H. W., \& Schreck, C. B. (2003). Effect of intraperitoneally implanted radio transmitters on the swimming performance and physiology of Pacific lamprey. North American Journal of Fisheries Management, 23, 1184-1192.
Coltherd, J. C., Morgan, C., Judge, J., Smith, L. A., \& Hutchings, M. R. (2010). The effect of parasitism on recapture rates of wood mice (Apodemus sylvaticus). Wildlife Research, 37, 413-417.

Cooke, S. J., \& O'Connor, C. M. (2010). Making conservation physiology relevant to policy makers and conservation practitioners. Conservation Letters, 3, 159-166.

Cucherousset, J., Marty, P., Pelozuelo, L., \& Roussel, J.-M. (2008). Portable PIT-detector as a new tool for non-disruptively locating individually tagged amphibians in the field: A case study with Pyrenean salamanders (Calotriton asper). Wildlife Research, 35, 780-787.

Cucherousset, J., Paillisson, J.-M., \& Roussel, J.-M. (2007). Using PIT technology to study the fate of hatchery-reared YOY northern pike released into shallow vegetated areas. Fisheries Research, 85, 159-164.

Cucherousset, J., Roussel, J.-M., Keeler, R., Cunjak, R. A., \& Stump, R. (2005). The use of two new portable 12-mm tag detectors to track small fish in shallow streams. North American Journal of Fisheries Management, 25, 270-274.

Cummins, C. P., \& Swan, M. J. S. (2000). Long-term survival and growth of free-living great crested newts (Triturus cristatus) pittagged at metamorphosis. Herpetological Journal, 10, 177-182.

D’Agostino, J. J., West, G., Boothe, D. M., Jayanna, P. K., Snider, T., \& Hoover, J. P. (2007). Plasma pharmacokinetics of selamectin after single topical administration in the American bullfrog (Rana catesbeiana). Journal of Zoo and Wildlife Medicine, 38, 51-54.

Delcourt, J., Becco, C., Vandewalle, N., \& Poncin, P. (2009). A video multitracking system for quantification of individual behavior in a large fish shoal: Advantages and limits. Behavior Research Methods, 41, 228-235.

Delcourt, J., Becco, C., Ylieff, M. Y., Caps, H., Vandewalle, N., \& Poncin, P. (2006). Comparing the EthoVision 2.3 system and a new computerized multitracking prototype system to measure the swimming behavior in fry fish. Behavior Research Methods, 38, 704-710.

Dennis, R. L., Newberry, R. C., Cheng, H.-W., \& Estevez, I. (2008). Appearance matters: Artificial marking alters aggression and stress. Poultry Science, 87, 1939-1946.

Denoël, M. (2007). Le Triton alpestre, Triturus alpestris (Laurenti, 1768). In J. P. Jacob, C. Percsy, H. De Wavrin, E. Graitson, T. Kinet, M. Denoël, et al. (Eds.), Amphibiens et Reptiles de Wallonie (pp. 62-71). Namur: Aves-Raînne \& Région wallonne.

Denoël, M., \& Andreone, F. (2003). Trophic habits and aquatic microhabitat use in gilled immature, paedomorphic and metamorphic Alpine newts (Triturus alpestris apuanus) in a pond in central Italy. Belgian Journal of Zoology, 133, 95-102.

Denoël, M., Bichot, M., Ficetola, G. F., Delcourt, J., Ylieff, M., Kestemont, P., et al. (2010). Cumulative effect of road deicing salt on amphibian behavior. Aquatic Toxicology, 99, 275280.

Denoël, M., Lena, J. P., \& Joly, P. (2007). Morph switching in a dimorphic population of Triturus alpestris (Amphibia, Caudata). Evolutionary Ecology, 21, 325-335.

Denoël, M., Mathieu, M., \& Poncin, P. (2005). Effect of water temperature on the courtship behavior of the Alpine newt Triturus alpestris. Behavioral Ecology and Sociobiology, 58, 121-127.

Directive 2010/63/EU of the European Parliament and of the Council of 22 September 2010 on the protection of animals used for scientific purposes. Text with EEA relevance. Official Journal of the European Union, 33-79.

Donnelly, M. A., Guyer, G., Juterbock, J. E., \& Alford, R. A. (1994). Techniques for marking amphibians. In W. R. Heyer (Ed.), Measuring and monitoring biological diversity: Standard methods for amphibians (pp. 177-284). Washington, DC: Smithsonian Institution Press. 
Eddins, D., Cerutti, D., Williams, P., Linney, E., \& Levin, E. D. (2010). Zebrafish provide a sensitive model of persisting neurobehavioral effects of developmental chlorpyrifos exposure: Comparison with nicotine and pilocarpine effects and relationship to dopamine deficits. Neurotoxicology and Teratology, 32, 99-108.

Faber, H. (1997). Der Einsatz von passiven integrierten Transpondern zur individuellen Markierung von Bergmolchen (Triturus alpestris) im Freiland. Mertensiella, 7, 121-132.

Faber, H. (2001). Individual recognition of amphibians with special emphasis on PIT (passive integrated transponders). Pianura, 13, $17-24$.

Fasola, M., Barbieri, F., \& Canova, L. (1993). Test of an electronic individual tag for newts. Herpetological Journal, 3, 149-150.

Fasulo, S., Marino, S., Mauceri, A., Maisano, M., Giannetto, A., D'Agata, A., et al. (2010). A multibiomarker approach in Coris julis living in a natural environment. Ecotoxicology and Environmental Safety, 73, 1565-1573.

Ferner, J. F. (2010). Measuring and marking post-metamorphic amphibians. In C. K. Dood Jr. (Ed.), Amphibian ecology and conservation: A handbook of techniques (pp. 124-141). New York: Oxford University Press.

Fraker, M. E. (2008). The effect of hunger on the strength and duration of the antipredator behavioral response of green frog (Rana clamitans) tadpoles. Behavioral Ecology and Sociobiology, 62, 1201-1205.

Gibbons, J. W., \& Andrews, K. M. (2004). PIT tagging: Simple technology at its best. Biosciences, 54, 447-454.

Giusi, G., Alo', R., Crudo, M., Di Vito, A., Facciolo, R. M., \& Canonaco, M. (2010). Environmental stressors and neurobiological features of marine teleosts: Histamine receptors as targets. Critical Reviews in Toxicology, 40, 620-632.

Greenstreet, S. P. R., \& Morgan, R. I. G. (1989). The effect of ultrasonic tags on the growth rates of Atlantic salmon, Salmo salar L., parr of varying size just prior to smolting. Journal of Fish Biology, 35, 301-309.

Gubili, C., Johnson, R., Gennari, E., Oosthuizen, H. W., Kotze, D., Meÿer, M., et al. (2009). Concordance of genetic and fin photo identification in the great white shark, Carcharodon carcharias, off Mossel Bay, South Africa. Marine Biology, 156, 2199-2207.

Hill, M. S., Zydlewski, G. B., Zydlewski, J. D., \& Gasvoda, J. M. (2006). Development and evaluation of portable PIT tag detection units: PITpacks. Fisheries Research, 77, 102-109.

Jehle, R., \& Hödl, W. (1998). Pits versus patterns: Effects of transponders on recapture rate and body condition of Danube crested newts (Triturus dobrogicus) and common spadefoot toads (Pelobates fuctus). Herpetological Journal, 8, 181-186.

Jemison, S. C., Bishop, L. A., May, P. G., \& Farrell, T. M. (1995). The impact of PIT-tags on growth and movement of the rattlesnake, Sistrurus miliarus. Journal of Herpetology, 29, 129-132.

Kato, S., Nakagawa, T., Ohkawa, M., Muramoto, K., Oyama, O., Watanabe, A., et al. (2004). A computer image processing system for quantification of zebrafish behavior. Journal of Neuroscience Methods, 134, 1-7.

Keck, M. B. (1994). Test for detrimental effects of pit tags in neonatal snakes. Copeia, 1994, 226-228.

Knaepkens, G., Maerten, E., Tudorache, C., De Boeck, G., \& Eens, M. (2007). Evaluation of passive integrated transponder tags for marking the bullhead (Cottus gobio), a small benthic freshwater fish: Effects on survival, growth and swimming capacity. Ecology of Freshwater Fish, 16, 404-409.

Kopecki, O., Vojar, J., \& Denoël, M. (2010). Movements of Alpine newts (Mesotriton alpestris) between small aquatic habitats (ruts) during the breeding season. Amphibia-Reptilia, 31, 109116.
Lacroix, G. L., Knox, D., \& McCurdy, P. (2004). Effects of implanted dummy acoustic transmitters on juvenile Atlantic salmon. Transaction of American Fisheries Society, 133, 211-220.

Lauzon-Guay, J.-S., \& Scheibling, R. E. (2008). Evaluation of passive integrated transponder (PIT) tags in studies of sea urchins: Caution advised. Aquatic Biology, 2, 105-112.

Lee, J., Park, I.-S., \& Cho, S. H. (2009). Long-term effects of passive integrated transponder tagging on the growth of olive flounder, Paralichthys olivaceus. Journal of the World Aquaculture Society, 40, 134-139.

Leggat, P. A., Smith, D. R., \& Kedjarune, U. (2007). Surgical application of cyanoracrylate adhesives: A review of toxicity. ANZ Journal of Surgery, 77, 209-213.

Mahapatra, K. D., Gjerde, B., Reddy, P. V. G. K., Sahoo, M., Jana, R. K., Saha, J. N., et al. (2001). Tagging: On the use of passive integrated transponder (PIT) tags for the identification of fish. Aquaculture Research, 32, 47-50.

Martin, E., Joly, P., \& Bovet, P. (1989). Diel pattern of activity in the Alpine newt (Triturus alpestris, Amphibia Urodela) during the aquatic phase. Biology of Behavior, 14, 116-131.

Martin, P., \& Bateson, P. (2007). Measuring behavior: An introductory guide (3rd ed.). Cambridge: Cambridge University Press.

May, R. (2004). Ethics and amphibians. Nature, 431, 403.

Mellor, D. J., Beausoleil, N. J., \& Stafford, K. J. (2004). Marking amphibians, reptiles and marine mammals: Animal welfare, practicalities and public perceptions in New Zealand. Wellington: Massey University, Department of Conservation.

Mesa, M. G., Bayer, J. M., \& Seelye, J. G. (2003). Swimming performance and physiological responses to exhaustive exercise in radio tagged and untagged Pacific lamprey. Transactions of the American Fisheries Society, 132, 483-492.

Moore, A., Russell, I. C., \& Potter, E. C. E. (1990). The effects of intraperitoneally implanted dummy acoustic transmitters on the behaviour and physiology of juvenile Atlantic salmon, Salmo salar L. Journal of Fish Biology, 37, 713-721.

Morley, C. G. (2002). Evaluating the performance of PIT tags and ears tags in capture-recapture experiment. New Zealand Journal of Zoology, 29, 143-148.

Mueller, R. P., Moursund, R. A., \& Bleich, M. D. (2006). Tagging juvenile Pacific lamprey with passive integrated transponders: Methodology, short-term mortality, and influence on swimming performance. North American Journal of Fisheries Management, 26, 361-366.

Navarro, A., Olivia, V., Zamorano, M. J., Ginès, R., Izquierdo, M. S., Astorga, N., et al. (2006). Evaluation of PIT system as a method to tag fingerlings of gilthead seabream (Sparus auratus L.): Effects on growth, mortality and tag loss. Aquaculture, 257, 309-315.

Newby, N. C., Binder, T. R., \& Stevens, E. D. (2007). Passive integrated transponder (PIT) tagging did not negatively affect the short-term feeding behavior or swimming performance of juvenile rainbow trout. American Fisheries Society, 136, 341-345.

Nicolaus, M., Bouwman, K. M., \& Dingemanse, N. J. (2008). Effect of PIT tags on the survival and recruitment of great tits Parus major. Ardea, 96, 286-292.

Ombredane, D., Baglinière, J.-L., \& Marchand, F. (1998). The effects of passive integrated transponder tags on survival and growth of juvenile brown trout (Salmo trutta L.) and their use for studying movement in a small river. Hydrobiologia, 371 (372), 99-106.

Ott, J. A., \& Scott, D. E. (1999). Effects of toe-clipping and PITtagging on growth and survival in metamorphic Ambystoma opacum. Journal of Herpetology, 33, 344-348.

Park, M. O., \& Park, I.-S. (2009). Long-term effects of passive integrated transponder (PIT) tagging on the kelp grouper Epinephelus bruneus. Journal of Fish Biology, 74, 285-288. 
Perret, N., \& Joly, P. (2002). Impact of tattooing and pit-tagging on survival and fecundity in the Alpine newt (Triturus alpestris). Herpetologica, 58, 131-138.

Pope, K. L., \& Matthews, K. R. (2001). Movement ecology and seasonal distribution of mountain yellow-legged frogs, Rana muscosa, in a high-elevation Sierra Nevada Basin. Copeia, 2001, 787-793.

Šamajová, P., \& Gvoždik, L. (2010). Inaccurate or disparate temperature cues? Seasonal acclimation of terrestrial and aquatic locomotor capacity in newts. Functional Ecology, 24, 1023-1030.

Schulte, U., Küsters, D., \& Steinfartz, S. (2007). A PIT tag based analysis of annual movement patterns of adult fire salamanders (Salamandra salamandra) in a Middle European habitat. Amphibia-Reptilia, 28, 531-536.

Scott, G. R., \& Sloman, K. A. (2004). The effects of environmental pollutants on complex fish behaviour: Integrating behavioural and physiological indicators of toxicity. Aquatic Toxicology, 68, 369-392.

Shuster, S. M., \& Wade, M. J. (2003). Mating systems and strategies. Princeton: Princeton University Press.

Sigourney, D. B., Horton, G. E., Dubreuil, T. L., Varaday, A. M., \& Letcher, B. H. (2005). Electroshocking and PIT tagging of juvenile
Atlantic salmon: Are there interactive effects on growth and survival? North American of Fisheries Management, 25, 1016-1021.

Sokal, R. R., \& Rohlf, F. J. (1995). Biometry: The principles and practice of statistics in biological research (3rd ed.). New York: Freeman.

Steinfartz, S., Stemshorn, K., Kuesters, D., \& Tautz, D. (2006). Patterns of multiple paternity within and between annual reproduction cycles of the fire salamander (Salamandra salamandra) under natural conditions. Journal of Zoology, 268, 1-8.

Sutherland, W. J. (1998). The importance of behavioural studies in conservation biology. Animal Behavior, 56, 801-809.

Statsoft-France (2010). Statistica (logiciel d'analyse des données), version 9.1 .

Winter, H. V., Jansen, H. M., Adam, B., \& Schwevers, U. (2005). Behavioural effects of surgically implanting transponders in European eel, Anguilla anguilla. In M. T. Spedicato, G. Lembo, \& G. Marmulla (Eds.), Aquatic telemetry: Advances and applications. Proceedings of the Fifth Conference on Fish Telemetry held in Europe (pp. 287-295). Rome: FAO/COISPA.

Wolfensohn, S., \& Lloyd, M. (2003). Handbook of laboratory animal management and welfare (3rd ed.). Oxford: Blackwell. 